\title{
The Study of Risk about International Oil Future Market
}

\author{
Xinshu Tu \\ School of Economics and Management, South China Normal University \\ Guangzhou 510006, China \\ E-mail: tuxinshu@126.com
}

\begin{abstract}
VaR is one of the best methods to measure the risk of international future markets; CVaR which is calculated by modifying $\mathrm{VaR}$ is a better way to measure the risk in excessive condition. There are unnumbered future markets in the world, and the risk of every sort is difference, we can calculate that the largest one is crude oil. Then we will compare its risk to its history and try to find out the trend risk changes. We find that the petroleum risk cycle more like the economy cycle of the U.S. When some famous historic affairs occur, the risk of that year is obviously larger through calculate the risk of future market. Also we can use CVaR to measure the risk when excessive incidents occur.
\end{abstract}

Keywords: VaR, Oil future market, Risk measurement

\section{Introduction}

Petroleum is one of essential sources of energy of human society in the nowadays, it has broad application in a lot of industry fields such as chemical industry, transportation, aerospace. In recent years, price continues going up, international petroleum price already becomes the key factor affecting world trends in economic development's with the fact that rising, oil that petroleum needs. Petroleum price fluctuation can affect to relevance industry. The quantity that a country's petroleum store is also having direct impact to country's economic security.

Exploit without the petroleum handling calling crude oil, since crude oil fluctuations in prices is acute, many countries all leads into crude oil futures to help pertinent enterprise to reduce risk. Influence is maximal be USA NYMEX crude oil futures. USA crude oil futures circumstances is already representing international crude oil price circumstances at present is becoming the undulate barometer of crude oil. Crude oil futures debuting also has double effect but, it can be that enterprise provides the implement evading oil price risk on one hand, but meanwhile enterprise event repeatedly enormous deficit happened in futures trading in crude oil judging that the fault can be used since to oil price. For calculating and managing risk effectively, need some science risk management method right away, VaR method among them is comparatively popular risk management method.

VaR method provides an indication of the possible maximum loss of a portfolio over a given time horizon at a certain confidence level (F.R. \& Miao, 2005). It originates from the fundamental mean - variance model that Markowitz founds in 1952. In 1980s, J.P. Morgan's Till Guldimann has brought forward the method with VaR management risk, but until 1994, the standardizing VaR is known to the public formally (Morgan, 1995). The Basel bank inspection committee announced 'relevant complement document being brought into marketplace risk factor in capital adequacy ratio' in April , 1995, makes the request suggesting that whose member bank takes inside VaR model as basis, calculating marketplace risk minimum capital requirement (Qin, Chen, Zou, 2005, pp. 12-16). VaR method has measured the lurking risk the portfolio formation that the risk factor affects is different. It has adapted to more and more complicated financial market trend. At present, VaR method is used already broadly cover west banking institution, has become the mainly method managing marketplace risk.

While but some exceeding risk condition such as unexpected event etc. appears, use VaR method to be able to underestimate risk sometimes. Within 'Conditional value-at-risk for general loss distributions' which written by R. Tyrrel Rockafeller and Stanislav Uryasev, the calculation principle according to VaR has brought forward one kind of new risk management method CVaR (condition value at risk) method therefore (R.T. \& S., 2002, pp. 1443-1471).It is the amendment the VaR method is carried out, is to the circumstance that exceeding price changes appear on the marketplace having inherited VaR method merit, being able to handle.

Have many at present about using VaR and CVaR to make the thesis that demonstration studies, at home and abroad, major part all are that the demonstration making stock market is analytical but, the research to future market is very few. According to the impact of American crude oil futures influence and crude oil over world economy, this article uses this two kind's risk management method to measure USA crude oil futures risk, and compare it with other main future contract in international future markets, then analyst the changing of USA crude oil futures risk.

\section{Mathematical formulation}

Value at risk $(\mathrm{VaR})$ provides an indication of the possible maximum loss of a portfolio over a given time horizon at 
a certain confidence level. Use formula to express by:

$$
\operatorname{VaR}=\inf \{f(x) \mid p(f(x)) \geq \alpha\}
$$

Where $f(x)$ is the lose function of portfolio, $\alpha$ is the certain confidence level. VaR is a figure, it expresses lurking risk been confronted with by portfolio. At present, calculating VaR's has mainly parting for three kinds, is that Deta- stable method, history simulation method and Monte Carlo simulation method. The invention of VaR improved the ability of risk measurement; it can do best in controlling financial risk. VaR looks like being able to do nothing when coming across the exceeding marketplace scene but, having needed to use CVaR at this time.

Rockafeller and Uryasev have brought forward one kind of new risk management method CVaR (condition value at risk) method which being based on VaR in 1999. It is the amendment the VaR method is carried out, is to the circumstance that exceeding price changes appear on the marketplace having inherited VaR method merit, being able to handle. CVaR can use formula to express by:

$$
C V a R=E[f(x) \mid f(x) \geq V A R]
$$

We can perceive CVaR being the average value exceeding the VaR loss. That CVaR and the VaR difference are CVaR not that a dividing line, but the tail assembly loses average value, it is sufficient to the measurement that the tail assembly loses.

\section{The history of oil fluctuation}

First, we watch two figures underneath, Figure 1 and Figure 2 is changing of American crude oil from1920 to 2005 and from 19782006 respectively. We can see from them obviously that the price of oil is stable in history, but from the ending of 1970s and being close to 30 years, international crude oil price became undulating acutely.

From the beginning of 19 centuries to the ending of 1960s, nominal crude oil price fundamental between 2.50 to 3.00 U. S. dollar/ barrels between. From 1958 to 1970, oil price stabilizes basically in 3 U. S. dollar/ barrels. 1973 Arab countries perform embargo on the Western countries, this feasible crude oil price has quadrupled, exceed $12 \mathrm{U}$. $\mathrm{S}$. dollar/ barrels. Then petroleum price stabilizes basically in $12 \mathrm{U}$. S. dollar to $14 \mathrm{U}$. S. dollar/ barrels between for 3 years. In September , 1980, Iraq assails Iran , the Iran-Iraq war outburst leads to petroleum output directly shrink by large margins , crude oil price walks highly from 14 U. S. dollar/ barrel single file of 1978 till 35 U. S. dollar/ barrel of 1981. Oil price continuing for goes up having stimulated the oil exploration being not the OPEC country and exploit an activity. From 1980 to 1986, be not that OPEC country daily outputs have increased by 10 million barrels. This period the whole world economy has appeared to decline, petroleum need has appeared to make fall, the supply and demand unbalance has made petroleum price also answer but fallen. To 1986, crude oil price falls till 10 U. S. dollar/ barrel following.

On January 2, 1990 troops of Iraq assault to Kuwait, bay circumstances escalates rapidly, therefore, the situation in the Middle East tension has brought about oil price going up by large margins, has fled from 20 original U. S. dollar/ barrels till 37 U. S. dollar/ barrels since Middle East area has concentrated oil-producing the world country. American president Bush has approved "the desert shield plan" on August 7, has decided to augment forces to the bay. Check USA military strength confidence henceforth, all of the world; anticipate that the bay tension may be over very quickly, therefore, after the bay deploys troops for battle, crude oil price begins to drop to return to the original price place in October.

With USA economy recovery and the development of Asia, the economy rising rapidly, the need to petroleum urge petroleum price to begin to climb slowly. Everyday the whole world petroleum amount of consumption increases to 6,200,000 barrels from 1990 to 1997, Asia consumed increasing accounting for nearly to halves, petroleum price continue rising until 1997. But, in 1998, the Asian financial crisis outburst has drawn the rest, Asia petroleum consumption for Asia economy fleetness increases by appear first since 1982 to go steadily downhill. The low fan who consumes and OPEC output increasing by, oil price pushed immediately to abyss. Although OPEC debuts the measure restricting output, oil price can only maintain in $25 \mathrm{U}$. S. dollar/ barrel vicinity.

With USA and the world economy getting warm again after a cold spell, in 2000, crude oil price continues working till the high point during the past 1981. But, under converging attack between the weakness of USA economy and being not that the OPEC country increases the production in 2001, petroleum price begins to glide. Especially after the ' 9.11 ', oil price slumps, immediate price has dropped in the middle ten days of a month in November $35 \%$.

But gradually with the fact that the world economy increase leading to increasing by that petroleum needs and petroleum producing country surplus producing energy in 2002, international crude oil price continues clambering rising, breaks 70 U. S. dollar/ barrels even on 2006. Since the surplus produces of OPEC states lower than 1 million 
barrels/day at present, the member state supplying breaks off any OPEC may initiate the world energy crisis. The marketplace has begun to become sensitive and fragile at this time, crude oil futures fluctuation and risk have enlarged (Ma, 2005).

\section{USA crude oil future market risk analysis}

All above has introduced the history of international crude oil fluctuations in prices and it's cause, we want to analyst the risk of USA crude oil market from two the angle underneath: first, comparing the risk of USA crude oil future market and the risk of other main futures market, and then coming to analyst the changing of USA crude oil future market during the last few years quantitatively. The data using in this part originates from 'Energy Information Administration' and 'fuyuan' software, the data handling software are 'Matlab 7.1' and 'Eviews 5.0'.

\subsection{USA crude oil comparison with other future's sort risk}

This part will choose comparatively some future markets for both at home and aboard, then measuring the risk of these sorts. They are: USA crude oil, USA gold, LME copper, Shanghai copper, Shanghai fuel oil. We choose the nearest data for 1 year, make use of formula $R_{\mathrm{t}}=\ln p_{\mathrm{t}}-\ln p_{\mathrm{t}-1}$ to calculate out these everyday breed earning ratio respectively, and then count the VaR and CvaR respectively (Wang, 2001). When calculating VaR and CvaR, since futures data existence 'heavy tail', it is unable to use Deta- stable method; we use the history simulation method and the Monte Carlo simulation method therefore respectively. Since future market can carry out two-way (buy and sell) trading, we count them respectively.

From the table upper we has measured the VaR and CVaR of some main future market, and we can get the following conclusion: (a) With regard to and for a short while paragraph of data, the result basic adopt Monte Carlo method and the history simulation method to calculate VaR and CVaR has been consistent, this has confirmed the Monte Carlo method scientific. (b) The risk of selling is greater than purchasing; this is to bring about from future price in recent years going up by a wide margin. (c) USA crude oil future market risk is max; its VAR is about $3 \%$, but CVAR can reach $4 \%$ or so. Just say, be in 20 business day inner, above one day let your deficit reach $3 \%$. Adopt dyadic lever business system besides since future market is common, caution money is in $10 \%$ following generally , this feasible risk one day appears on meeting more above the 10 times having been expanded, if coming across exceeding condition, within all loss possibility.

\subsection{Risk changes American crude oil forward market}

All above studies the lateral contrast USA crude oil future market risk and other futures sorts has been carried out, we want the change condition analyzing since crude oil price fluctuation leads to USA crude oil future market risk in history underneath. We choose WTI crude oil future market data from 1984 to 2006, figure making use of the history simulation law to calculate out VaR and CVaR, result from every age referring to from Figure 3 to Figure 6.

We can get the following conclusion from four artworks:

(a) As for the long range, the risk holding the paying and hold the selling is equal basically.

(b) The risk change displays cyclist, the figure above is it can be seen, from 1984 to 1992, VaR and CVaR have experienced from small to big then to small, also be from big to small from 1992 to now , this cyclists change trend and American economic cycle are well-balanced basically. When the conclusion that we get therefore is to think that economy raises high, crude oil futures risk also rises, crude oil futures risk can't reduce while the economic situation gets lost low.

(c) We can see that the age having two VaR abnormally composes in 1990 and 1986, which brought about by the Gulf War occur in1990, the international crude oil marketplace piles up in excess of requirement in 1986 and price drops by large margins. Since existence all affects significant petroleum price event in this two in age, fluctuations in prices is therefore very acute.

(d) We contrast VaR by CVaR, it is very different between VaR and CVaR in 1991. The cause lies in that exceeding risk condition has appeared in 1991. USA has unfolded the large-scale code name air raid action for the "desert storm" to Iraq in the morning of January 17, 1991, that very day USA crude oil marketplace has just dropped after opening quotation $23 \%$, only returning to normal in the business day following. This fluctuation extent in history is very rare in crude oil futures, even the ' 9.11 ' only can cause oil price undulates less than $8 \%$, "desert storm" action can be called exceeding condition.

This example has been testified while exceeding condition happened, the value of VaR having weakened obviously, having calculated out VaR insists to low VaR magnanimity risk effect obviously. At this time if using CVaR have been able to calculate out the marketplace risk truly, have testified therefore also the necessity using CVaR under exceeding situation. 


\section{Conclusion}

In this article we have introduced VaR and CVaR which are methods of measuring the risk of future market. Then we narrated the history of fluctuations in prices of international crude oil. After that we use VaR and CVaR method to compare USA crude oil and other main international future sorts' risk, and analyzed the change of VaR and CVaR of USA crude oil in history and its cause. We can see that the risk of WTI oil is larger than other futures sort; its risk fluctuation displays certain cyclists, and more sensitive compare to others.

Price of international crude oil still is in high position linger, it is very important now for relevant enterprises to know the risk of futures. Because of wide crude oil price fluctuation, some enterprises such as petroleum, chemical industry have making use of crude oil futures to carry out a hedge. In the process of participation international crude oil future market, only can we know risks in this market, and take appropriate measures evading risk, we have the ability reaching the expected effect in avoiding dangerous.

\section{References}

F.R. Harmantzis \& Miao, Linyan. (2005). On the Impact of Heavy-Tailed Returns to Popular Risk Measures : Evidence from Global Indices . America: Stevens Institute of Technology.

Ma, Yiqun. (2005). Five history mirrors shine upon new disturbance of oil price. [Online] Available: http://news. xinhuanet.com/fortune/2005-08/19/content_3375851_1.htm.

Morgan Bank J P. (1995). Risk Metrics Technical Manual. New York: J.P. Bank.

Qin Wanshun, Jin Yunhui \&Bu Yongxiang. Correlativity analyses the Chinese economic cycle and the international economic cycle. http://www.china.org.cn/ch-jjxc/14.htm.

Qin, Zheng, Chen, Shou \& Zou, Jianjun. (2005). VaR model reckoning and their valuation. System engineering. 7: pp. 12-16.

R.T. Rockafellar, S. Uryasev. (2002). Conditional value-at-risk for general loss distributions. Journal of Banking \& Finance. 26: pp. 1443-1471.

Wang, Chunfeng. (2001). Financial market risk administration. Tianjin: Press of Tianjin University.

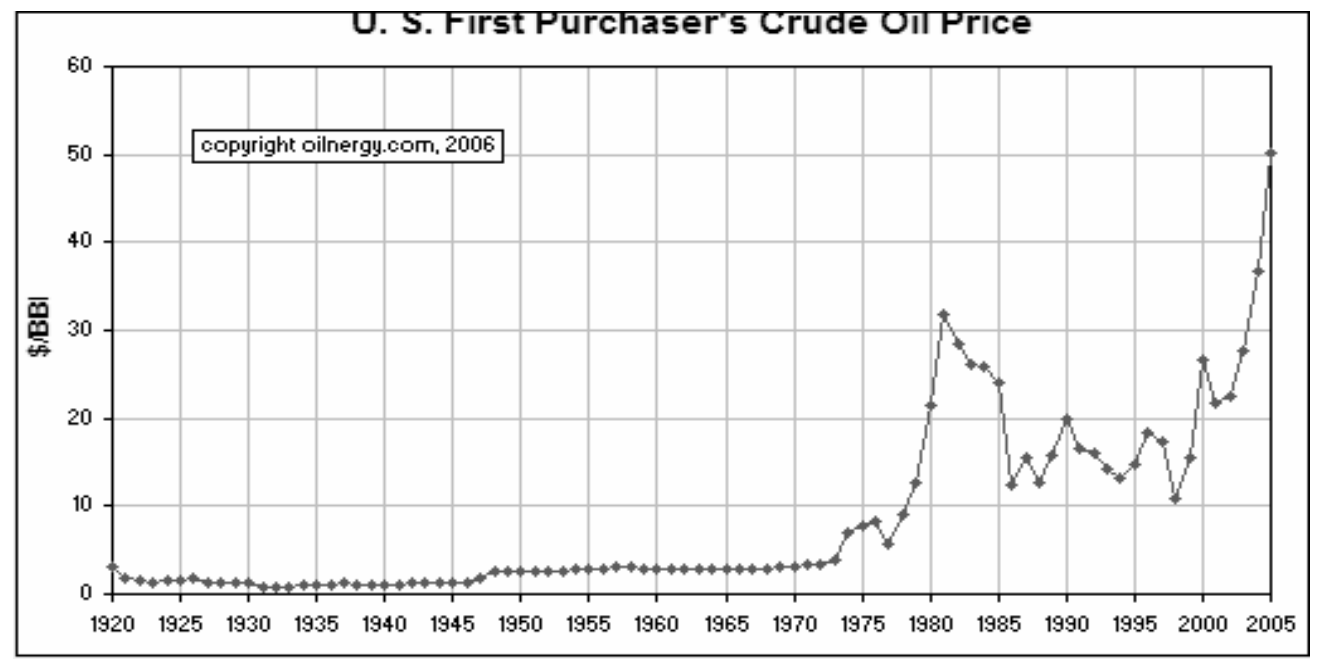

Figure 1. USA crude oil price(1920-2005) 


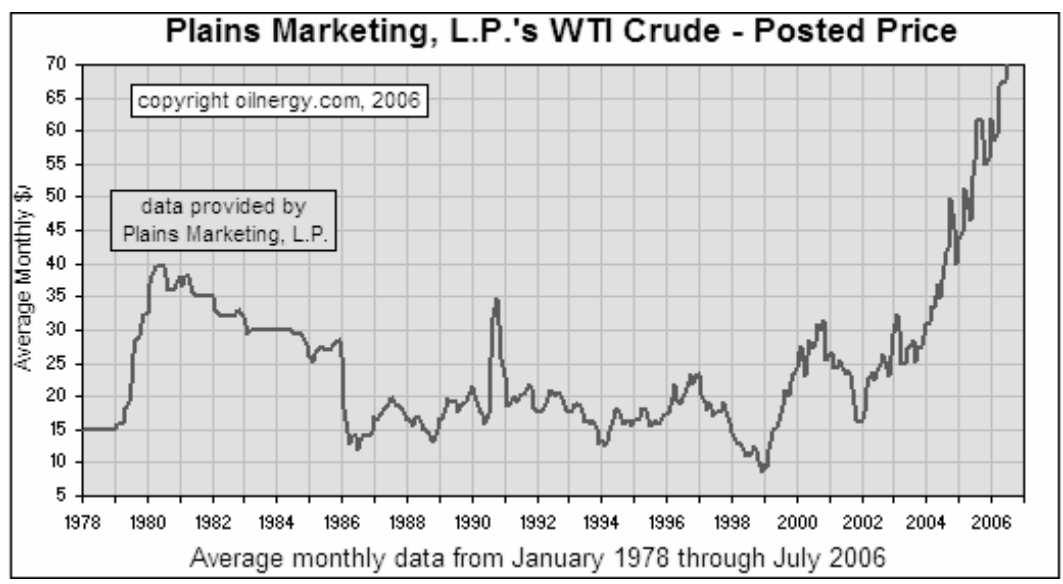

Figure 2. USA crude oil price (1978-2006)

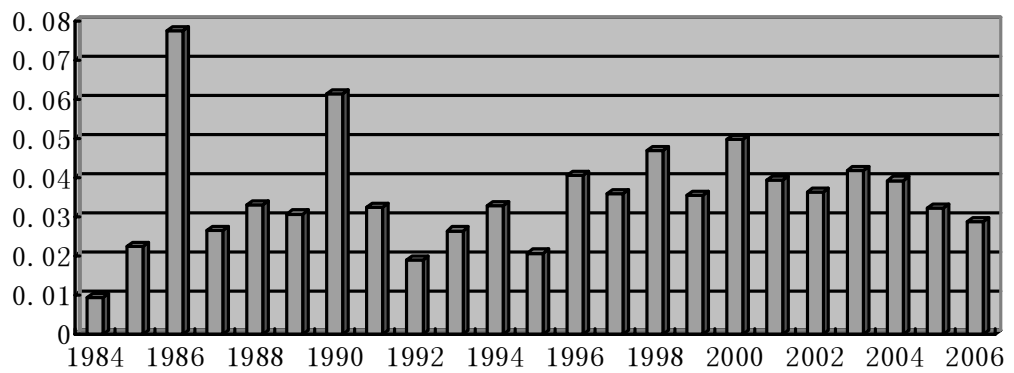

Figure 3.1984 holds VaR purchasing to 2006 over the years

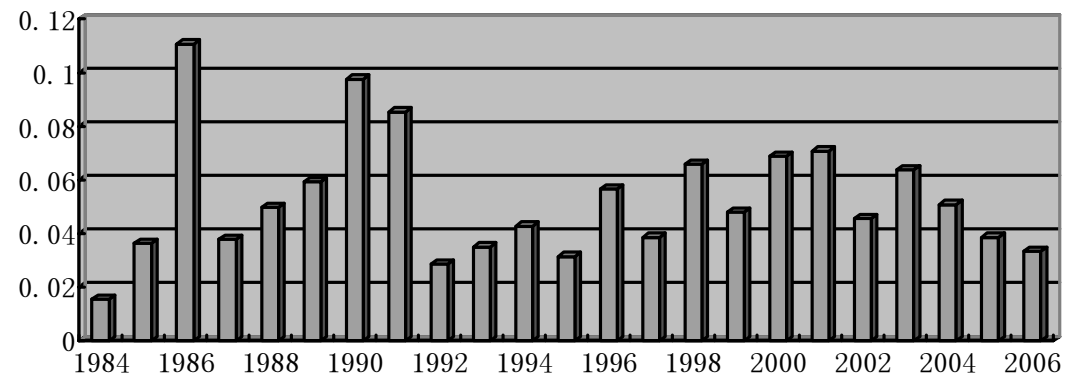

Figure 4. 1984 holds CVaR purchasing to 2006 over the years

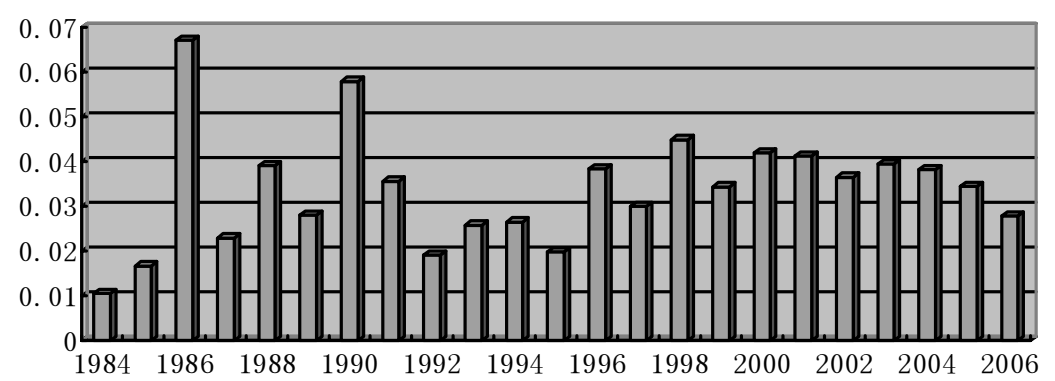

Figure 5. 1984 holds VaR selling to 2006 over the years 


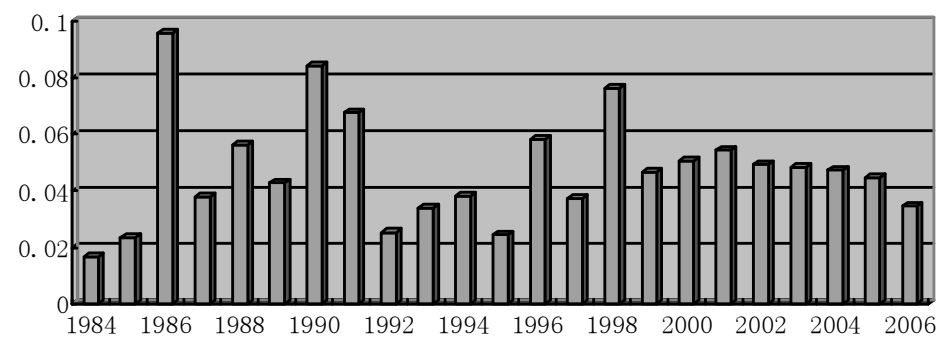

Figure 6. 1984 holds CVaR selling to 2006 over the years

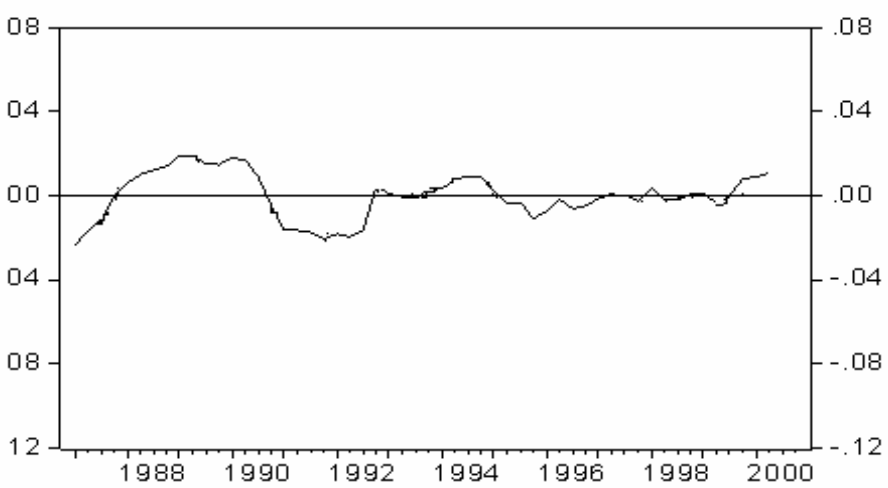

Figure 7. The USA economic cycle getting rid of the price trend (Qin, Jin, Bu)

Table 1 . Use history simulation method gains data

\begin{tabular}{|lcccc|}
\hline series & VaR(buy) & CvaR(buy) & VaR(sel) & CvaR(sell) \\
\hline WTI oil & 0.02845 & 0.03790 & 0.03791 & 0.04629 \\
USA gold & 0.01710 & 0.02803 & 0.02272 & 0.03043 \\
LME copper & 0.02338 & 0.03157 & 0.02841 & 0.04588 \\
SHFE copper & 0.02313 & 0.03664 & 0.03130 & 0.04171 \\
SHFE oil & 0.02265 & 0.03278 & 0.02404 & 0.03102 \\
CBOT bean & 0.02482 & 0.03516 & 0.02558 & 0.03456 \\
CZCE cotton & 0.00908 & 0.01250 & 0.01138 & 0.01495 \\
NYCE cotton & 0.02349 & 0.03578 & 0.03127 & 0.04349 \\
DCE bean & 0.01461 & 0.20957 & 0.01782 & 0.02286 \\
\hline
\end{tabular}

Table 2. Use Monte Carlo simulation method gains data

\begin{tabular}{|lcccc|}
\hline series & VaR(buy) & CvaR(buy) & VaR(sell) & CvaR(sel) \\
\hline WTI oil & 0.02830 & 0.03816 & 0.03157 & 0.03821 \\
USA gold & 0.02087 & 0.02748 & 0.01523 & 0.02070 \\
LME copper & 0.02338 & 0.03295 & 0.02427 & 0.03835 \\
SHFE copper & 0.02783 & 0.04772 & 0.02812 & 0.04572 \\
SHFE oil & 0.02365 & 0.03010 & 0.02802 & 0.03478 \\
CBOT bean & 0.02294 & 0.03134 & 0.02921 & 0.04424 \\
CZCE cotton & 0.00795 & 0.01772 & 0.00860 & 0.01098 \\
NYCE cotton & 0.02871 & 0.04250 & 0.02557 & 0.03548 \\
DEC bean & 0.01557 & 0.01976 & 0.01328 & 0.01875 \\
\hline
\end{tabular}

